\title{
Trend of declining bed net utilization among pregnant women in Ethiopia: new data from the Arba Minch Health and Demographic Surveillance System, 2010-2016
}

Teklemariam Gultie ${ }^{1 *}$, Gistane Ayele $^{2}$, Befikadu Tariku ${ }^{2}$, Mekdes Kondale $^{2}$, Zerihun Zerdo ${ }^{3}$, Behailu Merdekiyos $^{2}$, Tsegaye Tsalla ${ }^{3}$, Mesfin Kote ${ }^{2}$, Alemayehu Bekele ${ }^{4}$, Mulugeta Shigaz², Gebrekiros Gebremichael²,

Feleke Gebremeskel ${ }^{2}$ and Alazar Baharu ${ }^{5}$

\begin{abstract}
Background: Bed net utilization is one of the important methods of malaria prevention. Malaria during pregnancy is one of the fatal diseases which mostly leads to the death of the mother and the fetus. Some of the complications of malaria during pregnancy are: intrauterine growth restrictions, intrauterine fetal death, and stillbirth. The main challenge of malaria treatment is that most of the anti-malarial drugs are not safe to use during pregnancy. The use of bed net is the most effective method of prevention of malaria during pregnancy. There is a paucity of information on bed net utilization among pregnant women in the study setting. Hence, this study aims to assess the trends of bed net utilization among pregnant women in Arba Minch Health and Demography Surveillance Site (HDSS), Southern Ethiopia.

Methods: The study was conducted in the Arba Minch HDSS. The observation started in 2010 till 2016, using a repeated cross-sectional study design. The data was collected using interviewer administered questionnaire biannually with a total of 14 rounds of data collection from 2010 to 2016. A total of 2657 pregnant women were included in the study. Descriptive statistics such as frequency and proportion were used to present the findings of each variable.

Results: Out of 2657 mothers included in the study, more than half, 1521 (63.6\%), of the study participants were in the age group between 20 and 29 years. About one-third of the study population 793 (29.8) were having no schooling. The trend of bed net utilization decreased from $83.6 \%$ in 2010 to $36.5 \%$ in 2016.

Conclusion: The trends of bed net utilization decreased from 2010 to 2016 in Arba Minch HDSS. Utilization of bed net by pregnant women in the area need to be increased as it is malaria endemic. The government should strengthen the existing bed net distribution strategy. Further research is needed to investigate the cause of decreasing bed net utilization.
\end{abstract}

Keywords: Bed net, Malaria, Pregnant, Factors, Utilization

*Correspondence: tekledb2002@gmail.com

${ }^{1}$ Department of Midwifery, College of Medicine and Health Sciences, Arba Minch University, Arba Minch, Ethiopia

Full list of author information is available at the end of the article

\section{Background}

Malaria is the leading cause of morbidity and mortality in many developing countries. In 2018, an estimated 228 million cases of malaria occurred worldwide. An estimated 405,000 deaths due to malaria occurred in 2018 due to malaria with more than $94 \%$ of the malaria

(c) The Author(s) 2020. This article is licensed under a Creative Commons Attribution 4.0 International License, which permits use, sharing, adaptation, distribution and reproduction in any medium or format, as long as you give appropriate credit to the original author(s) and the source, provide a link to the Creative Commons licence, and indicate if changes were made. The images or other third party material in this article are included in the article's Creative Commons licence, unless indicated otherwise in a credit line to the material. If material is not included in the article's Creative Commons licence and your intended use is not permitted by statutory regulation or exceeds the permitted use, you will need to obtain permission directly from the copyright holder. To view a copy of this licence, visit http://creativeco mmons.org/licenses/by/4.0/. The Creative Commons Public Domain Dedication waiver (http://creativecommons.org/publicdomain/ zero/1.0/) applies to the data made available in this article, unless otherwise stated in a credit line to the data. 
deaths worldwide occurring in African region [1]. Each year, approximately 50 million women living in malariaendemic countries throughout the world become pregnant estimated 10,000 of these women and 200,000 of their infants die as a result of malaria during pregnancy [2]. Malaria remains the leading public health problem in Ethiopia. About $75 \%$ of the landmass of the country is malaria risk areas and $68 \%$ of the population are living in such settings [3].

Bed nets are one of the proven cost-effective components of malaria prevention through vector control approach. The use of a bed net during pregnancy is shown to reduce miscarriages and stillbirths by $33 \%$ [4]. Bed nets have been known to reduce numbers of infective mosquito bites by 70 to $90 \%$ in various geographical settings [5]. In Africa, bed nets compared with no nets reduced placental malaria in all pregnancies, reduced low birth weight and fetal loss in the first to fourth pregnancy [6]. Studies in Western Kenya had shown that bed nets were associated with reductions in the incidence of malaria parasitaemia and incidence of severe malarial anaemia [6]. Bed nets have been shown to be the most cost-effective measures in the prevention of malaria [2].

The prevention and control of malaria during pregnancy is, therefore, crucial as it helps to promote the health of the mother and her unborn child. Utilization of bed net among pregnant women varies from $15.8 \%$ in Shashogo District, Southern Ethiopia to $90.5 \%$ in Enugu, South Eastern Nigeria [8, 9]. Studies in different areas of Nigeria showed that utilization of bed nets among pregnant women is $44.2 \%$ in Ibadan, $35.3 \%$ in Imo, $21.3 \%$ in Edo state, and $44 \%$ nationwide [9-12]. Utilization of bed nets among pregnant women in Bungoma County Kenya is $82.5 \%$, Kilifi district, Kenya is $70.5 \%$, in Gulu Uganda is $35 \%$, in the Democratic Republic of the Congo is $78.4 \%$, in the Buea Health District, Cameroon is $83.4 \%$, Ghana is $20 \%$, and Sudan is $11.5 \%$ [12-18]. In different parts of Ethiopia bed net utilization among pregnant women indicated that 72.5\% in Damot Pulasa District, $23.2 \%$ in Oromia and Amhara Region, $73.3 \%$ in Eastern Ethiopia, $52.3 \%$ in Itang, Gambella region [3, 7, 9, 19]. The HDSS site is one of the malaria endemic area in the southern region of Ethiopia in which pregnant women and children are affected. The finding of the study will be used as an input for the government to further strengthen the already existing strategies of malaria prevention as well as a means for monitoring and evaluation of the performance of the government on bed net distribution. Therefore, this study aimed at assessing the trends of bed net utilization among pregnant women in Arba Minch HDSS from 2010 to 2016.

\section{Methods}

\section{Study setting and period}

The study was conducted in the Arba Minch Health and Demographic Surveillance System (HDSS) which was established in collaboration between Arba Minch University and Ethiopian Public Health Association with the support of CDC Ethiopia in 2009 with the aim of tracking demographic changes like death, birth, migration, and marital status change. The surveillance operates in the nine of 29 kebeles (smallest administrative unit) of Arba Minch Zuria District which is located in Gamo Zone, Southern Ethiopia. Arba Minch, the administrative town of the district is $505 \mathrm{~km}$ away from Addis Ababa in the southwest direction. Eight of the kebeles were selected based on the altitude (4 lowlands, 3 midlands and 1 highlands) and one of the kebele was selected as semiurban. The total population of the Arba Minch HDSS in 2009 and in 2015 was 65,057 (49.41\% female) and 71,890 ( $49.81 \%$ female), respectively. The data were collected from January 2010 to December 2016.

\section{Study design and sample size}

A community based repeated descriptive cross-sectional study was conducted in the Arba Minch HDSS. The Arba Minch HDSS is a set of operations that longitudinally follow well-defined entities or primary subjects (individuals, households, and residential units) and all related demographic and health-related outcomes within a clearly defined geographic area. The Arba Minch HDSS site follows-up every individual within a defined catchments area two times a year with house-to-house visits. All pregnant women living at Arba Minch HDSS were followed from 2010 to 2016. During this period, a total of 2657 pregnant mothers included in the study. The number of pregnant women included in each year are 214 in 2010, 340 in 2011, 439 in 2012, 368 in 2013, 212 in 2014, 460 in 2015, and 624 in 2016.

\section{Data collection procedure}

The data was collected using a structured interviewer administered questionnaire. The questionnaire was prepared by reviewing relevant literature and translated into the local language. The questionnaire included different socio-demographic and maternal health related variables as well as questions on the presence of bed net, the use of bed net and how they are using. Individuals and households have given identification numbers during the baseline enumeration and events updates are conducted biannually.

\section{Data quality assurance}

Data collectors and supervisors were trained on the data collection process and tools. The data collection process 
has been closely supervised by the field supervisors and the research team. Field workers (data collectors and supervisors) were from the local community members who were fluent in the local languages and who had completed at least secondary school education. Data collectors checked their own completed forms before they handed them over to their supervisors. The field supervisors checked the filled questionnaires and provided feedback to the data collectors. Moreover, data entry was made by data entry clerks with close supervision of data managers.

\section{Statistical analysis}

The data entered into the household registration system (HRS) 2 database system by data clerks and exported to Statistical package for the social sciences (SPSS) window version 25.0 statistical software. Final data cleaning was done by computing frequency and exploration through a whisker box plot for outliers. Descriptive statistics computed to determine the trend of bed net utilization. The result presented with text, tables, and graphs.

\section{Results}

\section{Socio-demographic characteristics of the study} participants

In this study, 2657 pregnant women were included. The mean age of the study population was $26 \pm 5$ years. The majority (63.6\%) of the pregnant mothers were in the age group of 20-29 years old. One-third of the mothers (29.8\%) have no schooling. One thousand six hundred seventy-six (63.1\%) of the mothers were housewives. Out of the 2657 pregnant women, 2439 (91.8\%) of the mothers were married. One thousand nine hundred fifteen (72.1\%) pregnant mothers were rural residents (Table 1).

\section{Trends of bed net utilization}

On average from 2010 to 2016 only 1255 (47.2\%) pregnant women utilized a bed net. The use of bed net over time starting from 2010 to 2016 decreased from 83.6 to $36.5 \%$ (Fig. 1).

\section{Discussion}

The aim of this study was to assess the trends of bed net utilization among pregnant women in Arba Minch. The 7 years of data (2010-2016) were analysed. One thousand two hundred fifty-five (47.2\%) pregnant women utilize the bed net. This finding is in line with the study finding in Northern Uganda (35\%) [11]. However, the finding is lower than the study finding from Bungoma Kenya (82.5\%), South Eastern Nigeria (90.5\%), Kilifi Kenya (70.5\%), Democratic Republic of Congo (78.4\%),
Table 1 Sociodemographic characteristics of pregnant women in Arba Minch HDSS, 2018 ( $N=2657)$

\begin{tabular}{llrr}
\hline Variables & Response categories & Frequency & Percent \\
\hline Age in years & $15-19$ & 249 & 10.4 \\
& $20-29$ & 1521 & 63.6 \\
& $30-39$ & 571 & 23.9 \\
Ethnicity & $>40$ & 49 & 2.1 \\
& Gamo & 1855 & 69.8 \\
& Zeyise & 193 & 7.3 \\
Educational status & Wolayita & 235 & 8.8 \\
& Other & \\
& No schooling & 774 & 14.0 \\
& Primary & 1691 & 29.8 \\
Marital status & Secondary or above & 173 & 63.7 \\
& Married & 2439 & 91.8 \\
Religion & Single & 218 & 8.2 \\
& Protestant & 2061 & 77.6 \\
& Orthodox & 558 & 21.0 \\
Residence & Other & & \\
& Rural & 38 & 1.5 \\
& Urban & 742 & 27.9 \\
\hline
\end{tabular}

${ }^{a}$ Amhara, Oromo, Gofa

${ }^{b}$ Catholic, Muslims, atheists

in Eastern Ethiopia (62.4\%), in Itang Ethiopia (52.3\%) $[9,10,13,14,16,20,21]$. The possible explanation for the discrepancy could be the government of Ethiopia has invested a lot to eradicate malaria, as a result, the magnitude of malaria infection in Ethiopia declined which make them give less attention to malaria prevention and the use of bed nets.

The overall trends of bed net utilization from 2010 to 2016 decreased from 83.6 to $36.5 \%$. However, after 2015, there was increasing utilization of bed nets among pregnant women. The reason for increasing bed net utilization could be due to a malaria epidemic in the study area in 2015.

\section{Conclusion}

The trend of bed net utilization among pregnant women decreased between 2010 to 2016. Pregnant women in the area need more supply and awareness of bed net utilization. The federal ministry of health should strengthen the existing bed net distribution strategies and monitor the utilization of bed net by the community. Further research is needed to investigate the cause of decreasing bed net utilisation. 


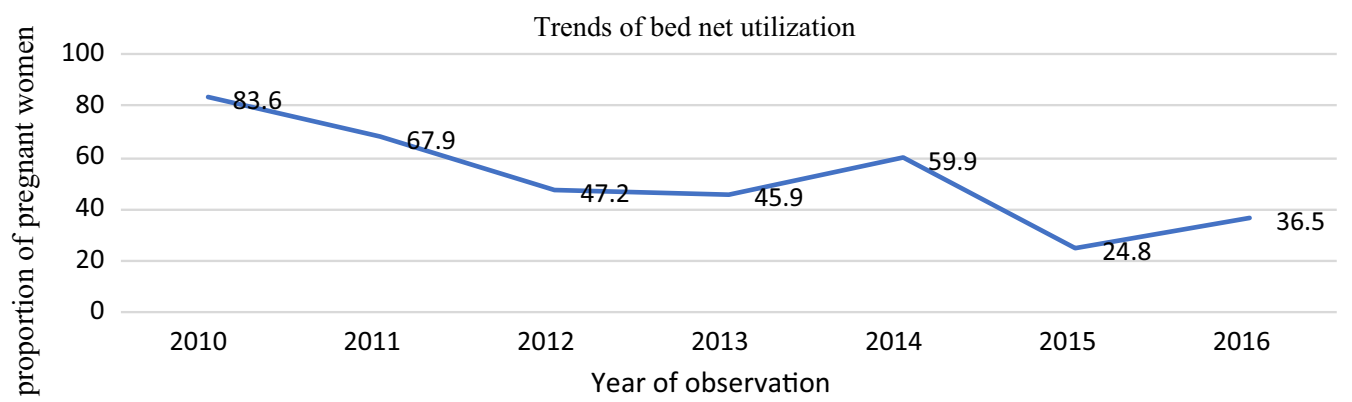

Fig. 1 Trend of bed net utilization among pregnant women in Arba Minch Zuria HDSS from 2010 to 2016

\section{Abbreviations}

HDSS: Health and Demographic Surveillance System; HRS: Household registration system; SPSS: Statistical package for social sciences.

\section{Acknowledgements}

The researchers would like to thank the data collectors and supervisors for their commitment and hard work. We would like to thank mothers participated in the study and Arba Minch University for financial support.

\section{Authors' contributions}

All the authors contributed equally to the design, analysis, and writing of the manuscript. All authors read and approved the final manuscript.

\section{Funding}

Arba Minch University financed the data collection process only with the support from the Ethiopian public health association.

\section{Availability of data and materials}

The datasets used and/or analysed during the current study are available from the corresponding author on reasonable request.

\section{Ethics approval and consent to participate}

Ethical approval obtained from Arba Minch University, an institutional research ethics review board. At the time of data collections, the study participants were informed about the benefit of the study, the right to opt questions not to answer. Finally, informed consent obtained from each participant. Confidentiality of the information kept by using anonymous code for each study participant.

\section{Consent for publication}

Not applicable.

\section{Competing interests}

The authors declare that they have no competing interests.

\section{Author details}

${ }^{1}$ Department of Midwifery, College of Medicine and Health Sciences, Arba Minch University, Arba Minch, Ethiopia. ${ }^{2}$ Department of Public Health, College of Medicine and Health Sciences, Arba Minch University, Arba Minch, Ethiopia. ${ }^{3}$ Department of Medical Laboratory Science, College of Medicine and Health Sciences, Arba Minch University, Arba Minch, Ethiopia. ${ }^{4}$ Ethiopian Public Health Association, Addis Ababa, Ethiopia. ${ }^{5}$ Department of Computer Sciences, Arba Minch University, Arba Minch, Ethiopia.

Received: 12 November 2019 Accepted: 28 March 2020

Published online: 08 April 2020

\section{References}

1. WHO. World malaria report 2019. Geneva: World Health Organization; 2019 .
2. WHO. Global malaria programme: pregnant women and infants. Geneva: World Health Organization; 2010.

3. Woyessa A, Deressa W, Ali A, Lindtjørn B. Ownership and use of long-lasting insecticidal nets for malaria prevention in Butajira area, south-central Ethiopia: complex samples data analysis. BMC Public Health. 2014;14:99.

4. Ghana Statistical Service. Ghana multiple indicator cluster survey with an enhanced malaria module and biomarker: monitoring the situation of the situtation and women in Ghana. Accra: Ghana Statistical Service; 2011.

5. Igwe PC, Inem V, Ebuehi OM, Bamgboye MA. The effect of insecticidetreated bed net use on malaria episodes, parasitemia and hemoglobin concentration among primigravidae in a peri-urban settlement in southeast Nigeria. J Rural Trop Public Health. 2007;6:25-32.

6. Gamble C, Ekwaru JP, Ter KFO. Insecticide-treated nets for preventing malaria in pregnancy. Cochrane Database Syst Rev. 2006;2:CD003755.

7. Fuge TG, Ayanto SY, Gurmamo FL. Assessment of knowledge, attitude, and practice about malaria and ITNs utilization among pregnant women in Shashogo District, Southern Ethiopia. Malar J. 2015;14:235.

8. Ugwu EO, Ezechukwu PC, Obi SN, Ugwu AO, Okeke TC. Utilization of insecticide-treated nets among pregnant women in Enugu, South Eastern Nigeria. Niger J Clin Pract. 2013;16:292-6.

9. Aluko JO, Oluwatosin AO. Utilization of insecticide-treated nets during pregnancy among postpartum women in Ibadan, Nigeria: a cross-sectional study. BMC Pregnancy Childb. 2012;12:21.

10. Ogbeide AO, Aruoture I, Wagbatsoma VA. Utilization of insecticidetreated net among pregnant women attending antenatal care in Etsuko east local government area of Edo State. J Med Biomed Res. 2014;13:106-16.

11. Ezeama M, Ezeamah F, Akor QG. Factors militating against the use of insecticide treated nets among pregnant women in Nigeria. Int J Res Med Health Sci. 2014;4:8-14.

12. Manu G, Boamah-Kaali EA, Febir LG, Ayipah E, Owusu-Agyei S, Asante KP. Low utilization of insecticide-treated bed net among pregnant women in the Middle Belt of Ghana. Malar Res Treat. 2017;2017:1-7.

13. Ndwiga T, Kei RM, Dancan OW. Utilization of insecticide treated bed nets among mothers attending MCH/FP in Webuye District Hospital, Bungoma County, Kenya. Open J Prev Med. 2014;4:470-80.

14. Njoroge FK, Kimani VN, Ongore D, Akwale WS. Use of insecticide-treated bed nets among pregnant women in Kilifi district, Kenya. East Afr Med J. 2009;86:314-22.

15. Obol JH, Ononge S, Orach CG. Utilisation of insecticide treated nets among pregnant women in Gulu: a post-conflict district in northern Uganda. Afr Health Sci. 2013;13:962-9.

16. Inungu JN, Onema W, Mumford V, Bolekela D, Ankiba N, Mukoso B, et al. Use of insecticide-treated mosquito net among pregnant women and guardians of children under five in the Democratic Republic of the Congo. Malar Res Treat. 2017;2017:5923696.

17. Nkesa S, Ndamukong-Nyanga J, Kimbi H, Atanga MB, Atashili J, Sumbele IU. Socio-demographic factors influencing the ownership and utilization of insecticide-treated bed nets among malaria vulnerable groups in the Buea Health District, Cameroon. BMC Res Notes. 2014;7:624. 
18. Yassin IM, Rosnah S, Osman M. Factors influencing the usage of insecticide-treated mosquito nets among pregnant women. Int J Health Res. 2010;3:139-44.

19. Teklemariam Z, Awoke A, Dessie Y, Weldegebreal F. Ownership and utilization of insecticide-treated nets (ITNs) for malaria control in Harari National Regional State, Eastern Ethiopia. Pan Afr Med J. 2015;21:52.

20. Watiro AH, Awoke W. Insecticide-treated net ownership and utilization and factors that influence their use in Itang, Gambella region, Ethiopia: cross-sectional study. Risk Manag Healthc Policy. 2016;9:101-12.
21. Biadgilign S, Reda A, Kedir H. Determinants of ownership and utilization of insecticide-treated bed nets for malaria control in Eastern Ethiopia. J Trop Med. 2012;2012:235015.

\section{Publisher's Note}

Springer Nature remains neutral with regard to jurisdictional claims in published maps and institutional affiliations.
Ready to submit your research? Choose BMC and benefit from:

- fast, convenient online submission

- thorough peer review by experienced researchers in your field

- rapid publication on acceptance

- support for research data, including large and complex data types

- gold Open Access which fosters wider collaboration and increased citations

- maximum visibility for your research: over $100 \mathrm{M}$ website views per year

At BMC, research is always in progress.

Learn more biomedcentral.com/submissions 